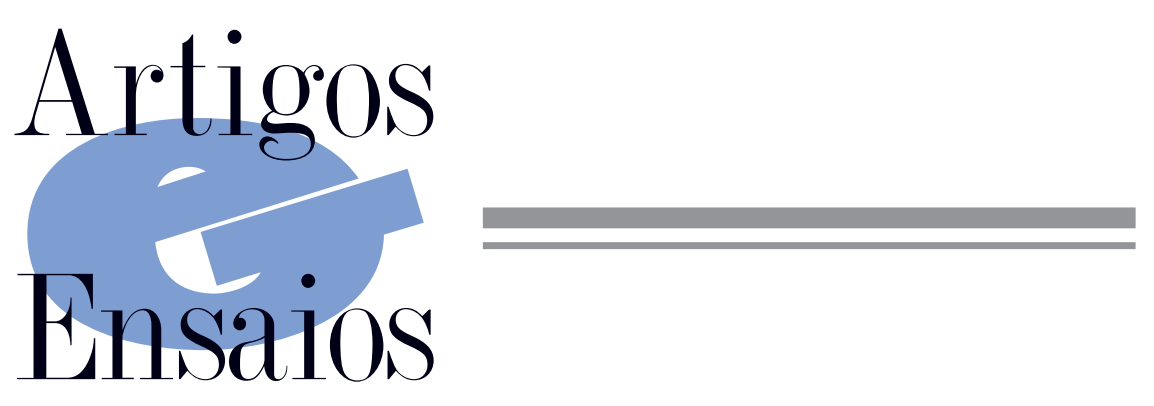

\section{CINEMA E TV NO BRASIL: BREVE PANORAMA A PARTIR DA CRIAÇÃO DA GLOBO FILMES}

\section{Juliana Sangion}

Nos últimos anos, o público brasileiro - majoritariamente habituado aos padrões televisivos - passou a encontrar forte identificação temática e estética das produções televisivas com os filmes brasileiros que alcançaram o circuito exibidor comercial. Apesar de bastante difundida, porém, é equivocada a afirmação de que todo cinema feito no país atualmente tem tais características.

O que de fato ocorre é que são justamente os filmes com as maiores bilheterias, aqueles que partilham desse hibridismo. Por trás da imensa maioria desses filmes está a marca da Globo Filmes, desde o início da primeira década de 2000.

Se por um lado é arriscada a afirmação de que não há cinema sem apoio da Globo Filmes, - considerando que há várias propostas diferentes sendo produzidas no país - por outro lado está claro que sua entrada no mercado consolidou uma forma específica de fazer cinema: a pensada a partir e para um público acostumado à televisão.

Para além de comentar o hibridismo estético, é importante analisar o atual contexto do audiovisual brasileiro, mais especificamente sob o enfoque da relação cinema-TV e dos conceitos da economia criativa. Considerando também as obras que recebem apoio de divulgação no lançamento, a Globo Filmes aumentou sua produção de dois a três filmes no início das operações, em 1998, para cerca de 17 filmes por ano atualmente: a cada 25 dias, há uma campanha de um filme brasileiro no ar na televisão. Quando a Globo Filmes estreou no setor cinematográfico, o market share da produção nacional girava em torno de 6 a $7 \%$ do mercado brasileiro. Na fase em que a Globo Filmes se consolidou, em 2003, os filmes brasileiros chegaram a representar 21,4\% do mercado. Apesar da situação não ter se mantido (oscilando em torno de 12\% na fase seguinte), em 2010 bateu $19 \%$ enquanto, no ano seguinte, o share de mercado do filme nacional recuou para $12,6 \%$.

COMUNICAÇÃO E CULTURA: NOVAS CONFIGURAÇÕES A criação da Globo Filmes pelas Organizações Globo, em 1998, e seu modo de atuação no mercado, foram favorecidos por elementos econômicos e por uma série de outros fatores socioculturais e políticos. Ao longo dos últimos 40 anos, o cenário empresarial brasileiro na área de comunicação se desenhou favoravelmente para que ocorresse a redundância de conteúdos em diferentes mídias, ou a chamada reciclagem audiovisual, como propõe André Gatti (1). E, não por acaso, foi a Globo a empresa que obteve maior êxito ao entrar em diferentes setores da comunicação audiovisual. A redundância de conteúdos em diferentes plataformas, no caso da Globo, ocorre quando seu braço cinematográfico produz ou coproduz filmes com uma fórmula já utilizada pela TV, transformando séries e programas já existentes em produções para o cinema (Os normais, A grande família). Ou quando adapta filmes de sucesso no cinema, para a TV (Cidade dos homens, Carandiru, Chico Xavier). Interessante notar que, da mesma maneira, há repetição das técnicas de trabalho. Diretores de TV da emissora, por exemplo, têm seus projetos aprovados para dirigir filmes, além de técnicos e de vários atores do elenco de novelas e outros programas. Neste caso, a especialização e o know-how da empresa facilitam a redundância.

Para melhor refletir sobre a situação atual da comunicação 


\section{Artigos \& Ensaios}

de massas no Brasil é necessário resgatar alguns aspectos da história e dos elementos que a compõem. O crescimento vertiginoso da Globo e o poder conquistado por ela na área em que atua estão diretamente relacionados ao desenvolvimento do processo histórico do setor audiovisual no país. Dos 20 filmes com maior bilheteria do cinema nacional no período de 2000 a 2011, apenas dois não tiveram o selo da Globo Filmes. Atualmente, a empresa já passou a marca de 120 milhões de espectadores, com cerca de 150 filmes lançados desde 1998.

O crescimento das Organizações Globo foi permeado, ao Iongo dos anos, por um discurso que justificava sua hegemonia, apoiado na competência empresarial, no nacionalismo e na competência técnica, este último pilar que sempre mereceu destaque na comunicação institucional do grupo. Nesse contexto, é interessante notar o percurso do campo audiovisual, saindo da esfera social para o âmbito comercial, sendo praticamente engolido pelas lógicas de mercado, como acontece há anos com os grandes conglomerados midiáticos em todo o mundo. A comunicação social, mais especificamente os meios e produtos audiovisuais, torna-se cada vez mais um bem de mercado instalado no âmbito da Organização Mundial do Comércio (OMC) (2). Mais que um agente econômico, o campo audiovisual, notadamente a televisão, assumiu um papel de agente político na sociedade contemporânea, como destacou o sociólogo Octavio lanni, em O príncipe eletrônico (2000), ao afirmar que o veículo configura-se em um dos mais importantes "príncipes eletrônicos do século XX", em referência às obras dos italianos Maquiavel, em O príncipe, e Gramsci, em O moderno príncipe. Para lanni, "trata-se de um meio de comunicação, informação e propaganda presente, ativo no cotidiano de uns e outros, indivíduos e coletividades, em todo o mundo. Registra e interpreta, seleciona e enfatiza, esquece e sataniza o que poderia ser a realidade e o imaginário. Muitas vezes, transforma a realidade, seja em algo encantado ou escatológico, em geral virtualizando a realidade, em tal escala que o real aparece como forma espúria do virtual" (3).

Segundo o sociólogo, a importância das empresas e conglomerados de mídia na organização sistêmica em que se assenta grande parte da integração social, que prevalece no mundo, reside especialmente no fato de que essa organização se baseia no modo pelo qual a própria mídia atua.

A oferta do conteúdo fílmico em diferentes plataformas, além das salas de cinema, que presenciamos hoje, se apro- xima em certo sentido ao descrito por Canclini sobre os processos de desterritorialização e descolecionamento - frutos da pós-modernidade - que geram contradições entre as utopias de criação autônoma na cultura e a industrialização dos mercados simbólicos, na medida em que "a proliferação de dispositivos de reprodução faz com que se percam as coleções, se desestruturem as imagens e (especialmente nesse caso) os contextos, as referências semânticas e históricas que amarravam seus sentidos" (4). É justamente na pós-modernidade onde presenciamos as formas mais concentradas de acumulação de poder e centralização transnacional da cultura que a humanidade já conheceu.

A reprodução pós-moderna muda os contextos, desterritorializa. O deslocamento cultural pelo qual passa o cinema brasileiro se dá em relação às novas plataformas, principalmente em relação à televisão. Esta tem substituído os filmes não somente no tempo livre do público, mas também no espaço dos cinemas, quando os filmes assumem uma estética e uma linguagem inerente muito mais à televisão do que ao padrão cinematográfico tradicional.

Tomemos como exemplo o caso de Antônia (2007), produção de Tata Amaral. Antes de série de TV, Antônia era para ter sido um filme. A ideia inicial da diretora era lançar Antônia nos cinemas e somente depois transformá-la em série. Porém, sem verba para finalizar e distribuir o filme já rodado, Tata procurou a produtora 02, de Fernando Meirelles, que abraçou a ideia, mas sugeriu que o filme ficasse para depois, Antônia estreou na TV Globo em novembro de 2006, exibido semanalmente, às sextas-feiras, e chegou a atingir 32 pontos de audiência na estreia. No entanto, o deslocamento da TV para o cinema, nesse caso, foi um fracasso. O filme estreou nos cinemas em fevereiro de 2007, mas não foi sucesso de bilheteria; pelo contrário, não chegou a 80 mil espectadores.

ESTRATÉGIA DE NEGÓCIO A decisão da Globo em expandir seus negócios para o mercado cinematográfico pode ser entendida como uma estratégia de crescimento econômico, utilizada por muitas empresas de comunicação. Com a busca de oportunidades em mercados novos, a empresa diversifica os riscos de seus investimentos, além de ter a possibilidade de reduzir custos, já que passa a utilizar o know-how e boa parte da estrutura que possui para a atuação no novo mercado e a ampliar os espaços para anunciantes.

As estratégias de crescimento econômico podem ser tanto externas - como é o caso das fusões, absorções e alianças 


\section{Artigos \& Ensaios}

com outras empresas do mesmo setor ou de setores afins - como internas. O caso Globo encontra ressonância na chamada economia de sinergia, na qual há redução de custos devido à produção de bens relacionados. Neste caso, a produção audiovisual - filmes para cinema, para os canais de TV aberta e fechada da emissora, para DVD etc.

Além de aproveitar o conteúdo, a Globo também se vale de toda uma estrutura já montada para a promoção do filme em seus programas de televisão e de uma forte e ampla rede de contatos com atores, diretores e produtores. Fatores estes que beneficiam a redução de custos e facilitam mecanismos para a empresa financiar-se, já que os filmes representam uma fonte nova de renda com publicidade cada vez que são exibidos em meios diferentes. Ocorre uma otimização do ganho com a venda de espaços publicitários a partir de um mesmo conteúdo.

Desde o início de sua história, a partir de uma visão claramente voltada para a excelência nos negócios e buscando a consolidação no mercado, a TV Globo teve de construir suas estruturas industriais para alimentar a programação. Diferentemente do que ocorria nos Estados Unidos, onde uma produção cinematográfica forte e consolidada apoiava com conteúdos a televisão, no Brasil praticamente inexistia tal intercâmbio. Assim, a integração vertical já aparece nas décadas iniciais da Globo. Tal integração possibilitava à emissora, o controle do produto, a internacionalização das atividades e a redução dos custos (5). Um exemplo da industrialização bem sucedida da TV Globo e que alavancou a empresa como expoente do setor audiovisual no imaginário do brasileiro está na produção das telenovelas e minisséries.

Um dos destaques é a novela Escrava Isaura, de Gilberto Braga, que foi ao ar pela TV Globo em 100 capítulos, entre 1976 e 1977. No final de 1985, Escrava Isaura já havia sido vendida para 27 países. Mesmo quase 40 anos após sua estreia, ela ainda está na lista das novelas mais comercializadas no exterior. Já foi exibida sete vezes na França, cinco na Alemanha e três na Suíça e chegou a países africanos como Congo, Gabão, Gana e Zimbábue. Na própria Globo, a novela foi reapresentada algumas vezes.

Outro exemplo de grande sucesso, do fim da década de 1970, é Dancin' Days. Este ano, a TV Globo se juntou à rede portuguesa SIC na coprodução da versão portuguesa da novela, cujas gravações em Portugal começaram em março. A novela - também de autoria de Gilberto Braga -, exibida pela TV Globo entre 1978 e 1979, marcou época no Brasil e no exterior. Foi a primeira novela brasileira a ser exibida no México, país com forte tradição na produção de teledramaturgia e um dos maiores exportadores mundiais desse conteúdo. Dancin' Days foi apresentada em cerca de 40 países, de acordo com dados da Globo.

Foi exatamente nos anos de 1970 que a TV Globo conseguiu chegar à expansão internacional com a venda de algumas telenovelas e a participação em eventos internacionais de comercialização de conteúdos. Isso foi possível graças à consolidação de uma estrutura de produção de novelas e minisséries por meio do investimento em várias frentes, como inovação tecnológica e formação/treinamento de pessoal técnico, uso racionalizado dos estúdios, construção de cenários, busca de criadores culturais de diferentes áreas para sofisticar o padrão da dramaturgia.

Há bastante polêmica quando se questiona o uso do saber-fazer na TV aplicado ao cinema.

Está claro que o uso do mesmo formato para ambos os meios tem o objetivo de atrair para o cinema um público já familiarizado com o que vê na televisão, tendo assim, uma possibilidade maior de rentabilidade também no novo suporte.

Os espectadores, encarados aqui como clientes, representam grande oportunidade de outro tipo de sinergia: sinergia de base de clientes. "(...) um grupo de comunicação possui informações sobre o mercado em que investe e pode oferecer-Ihe diferentes produtos de sua propriedade (...)" (6).

HISTÓRIA A criação da Globo Filmes se insere numa perspectiva da empresa de atenção às novas mídias, surgida a partir da metade dos anos de 1990. O cinema foi considerado como mais uma das plataformas em que as Organizações Globo deveriam atuar como produtora de conteúdo. A ideia partiu da diretora Marluce Dias, da Rede Globo. É importante notar como o "negócio Globo Filmes", evidenciado por meio de sua estrutura organizacional e hierárquica, se insere totalmente no campo televisivo: suas decisões são tomadas e influenciadas pela direção da TV Globo, tendo como um dos benefícios a infraestrutura da empresa, tanto física como de capital humano e know-how.

Do ponto de vista de negócio, a estratégia era criar e fortalecer um público consumidor de conteúdo, o "espectador do futuro", apoiada nos hábitos de consumo dos jovens.

Para Carlos Eduardo Rodrigues, diretor-executivo da Globo Filmes, a filosofia definida em sua criação era que a Globo estivesse onde seu telespectador estivesse. 


\section{Artigos \& Ensaios}

CONCLUSÃO Procuramos mostrar a maneira de encarar o mercado audiovisual adotada pela Globo Filmes, por meio de estratégias oriundas de negócios de outras naturezas e que foram, ao longo dos anos, sendo incorporadas pelas indústrias culturais, que no Brasil têm seu expoente no caso das Organizações Globo - ícone empresarial de qualidade na indústria do audiovisual.

Quando o meio midiático incorpora formatos corporativos, vemos estratégias comerciais que assumem um caráter agressivo do ponto de vista empresarial, as quais podem ser identificadas claramente na atuação da Globo Filmes. Dentre os efeitos dessa "empresarialização" temos que a necessidade de adequar as propostas comunicativas às exigências do consumo geram processos de padronização. Desta maneira, reduzem-se as especificidades e aumentam as chances de o conteúdo circular mais facilmente em circuitos comerciais que requerem produtos bastante homogêneos (7).

Em suma, o modelo de economia de cinema no Brasil, marcado pela competição deficiente, ainda que fomentasse a produção, deixava as empresas produtoras brasileiras carentes de maior apoio para as fases de promoção, distribuição e exibição dos filmes. Enfrentar um mercado interno altamente oligopolizado nesse quesito, além de concorrer com o filme estrangeiro hegemônico da indústria norte-americana, fez com que empresas e governo não conseguissem alavancar um projeto de indústria para o cinema nacional e contribuiu para o surgimento e consolidação de um projeto como o da Globo Filmes.

Dados da Ancine (Agência Nacional do Cinema) mostram que entre 2001 e 2009, a produção de filmes brasileiros cresceu cerca de 160\%. Mas a entrada da Globo no cinema alterou o cenário audiovisual, para além das estatísticas acima. Alterou seus diferentes aspectos: produção, distribuição, exibição, relação entre profissionais, conteúdo estético e narrativo etc. Na produção e posteriormente na distribuição, o filme nacional fica dependente da associação a grandes produtoras e a agentes financeiros de grande poder - as chamadas majors -, de um lado e, de outro, ao maior grupo de comunicação audiovisual do país, que detém alto poder midiático. Praticamente apenas os filmes que se associam às megacorporações do entretenimento e à Rede Globo, por meio da Globo Filmes, conseguem ser competitivos.

Na relação entre profissionais, presenciamos o surgimento de uma nova geração de realizadores audiovisuais. Formada em um período em que a produção cinematográfica nacio- nal estava praticamente estagnada, essa geração migrou para a televisão e para a publicidade. Hoje, esses profissionais transitam pelas diferentes plataformas, trocam informações e experimentam novas formas estéticas e de produção. Com relação aos conteúdos, temos que a divisão entre linguagens e indústrias - cinematográfica e televisiva está em seu momento mais frágil. Tem sido cada vez mais difícil não identificar características de um meio inseridas em outro, o que acaba por criar novos parâmetros audiovisuais. O resultado do hibridismo da película com o digital, para além das fronteiras tênues entre os campos, é a percepção de um cinema mais eletrônico e uma televisão percebida como sendo de maior qualidade, ao ficar com "cara" de cinema.

O público brasileiro mais consolidado é, sem dúvida, o formado por telespectadores - habituados aos padrões da teledramaturgia produzidos por e para essa mídia-, muito mais que de espectadores de cinema. Portanto, o próprio consumo doméstico de televisão que, ao longo da história do audiovisual nacional ameaçou o cinema, hoje ajuda a alavancar a audiência, no que se consolidou como a principal estratégia da Globo Filmes. O que não se pode afirmar com certeza é até quando essa fórmula funcionará.

Juliana Sangion éjornalista, doutora em multimeios pela Unicamp e professora na área de audiovisual da PUC-Campinas.

\section{REFERÊNCIAS BIBLIOGRÁFICAS}

1. Gatti, A.. "O mercado cinematográfico brasileiro: uma situação global?” In: Meleiro, A. (org.). Cinema no mundo: Indístria, política e mercado: América Latina. São Paulo. Escrituras, 2007. p. 137, vol 2.

2. Leal Filho, L.. "Sociedade e televisāo". In: Brittos, V. C.; Cabral, A. (orgs.). Economia politica da comunicação: interfaces brasileiras. Ed. e-papers, 2008. p. 195.

3. Ianni, O. "O príncipe eletrônico". In: Dowbor, L. et al. (orgs.). Desafios da comunicação. São Paulo.Ed. Vozes, 2000. pp. 65-66.

4. Canclini, N.G. Culturas hibridas: estratégias para entrar y salir de la modernidad. México DF. Editorial Grijalbo, 1990, p. 25.

5. Ramos, J.M.O. Cinema, televisão e publicidade: cultura popular de massa no Brasil nos anos 1970-1980. São Paulo. Annablume, 2004, p.45.

6. Bustos, J.C.M. "Estrategías de los grupos de comunicación en la era de la convergencia”. In: Bolano, C.; Mastrini, G.; Sierra, F. (eds.). Economía política, comunicación y conocimiento: una perspectiva crítica latinoamericana. La Crujía, 2005.

7. Martín-Barbero, J. Os exercícios do ver: hegemonia audiovisual e fiç̧ão televisiva. São Paulo: Editora Senac, 2001, p. 77. 